\title{
Effect of Nitrogen Flow Rate on Structure and Adhesion Strength of Magnetron Sputtered Ti-Si-N Nanocomposite Films
}

\author{
Chunlin $\mathrm{HE}^{\mathrm{a}}$, Leipeng XIE, Yuechang ZHU, Rui LI, Guofeng MA, Jianming WANG \\ Liaoning Provincial Key Laboratory of Advanced Materials, Shenyang University, Shenyang 110044, \\ China \\ accllhhe@126.com
}

\begin{abstract}
Ti-Si-N nanocomposite films were prepared by co-sputtering Ti and $\mathrm{Si}$ targets in $\mathrm{Ar} / \mathrm{N}_{2}$ gas atmosphere. The effect of $\mathrm{N}_{2}$ flow rate on the structure, adhesion strength and friction coefficient of the deposited films was studied by using X-ray diffraction, atom force microscope, field emission scanning electron microscopy and multi-functional tester for material surface properties. The Ti-Si-N films had a fine, smooth and compact structure with TiN nanograins embedded in an amorphous $\mathrm{Si}_{3} \mathrm{~N}_{4}$ matrix. The nanocomposite films exhibited (200), (111), (220) and (222) reflections with a dominant orientation of the (200) reflection. When the $\mathrm{N}_{2}$ flow rate increased, the film structure was refined. It was found that both interfacial adhesion strength and friction coefficient depended on the $\mathrm{N}_{2}$ flow rate, and the best values were exhibited by the nanocomposite film produced at $\mathrm{N}_{2}$ flow rate of $15 \mathrm{sccm}$, perhaps contributed to a finer and smoother structure of this deposited film.
\end{abstract}

Keywords: Ti-Si-N, Sputtering, Nanocomposite film, Microstructure, Adhesion strength, Friction coefficient

\section{Introduction}

Titanium nitride is one of the most used materials as hard films because of its high hardness, wear resistance and chemically stability [1]. These films are generally prepared by magnetron sputtering and arc ion plating. The mechanical properties of TiN thin films can be improved through alloying TiN with C, B or Al, Zr etc [2]. Since Veprek [3-5] obtained the Ti-Si-N nanocomposite films via chemical vapor deposition with a hardness of $105 \mathrm{GPa}$, Ti-Si-N nanocomposite films have been paid much attention [6-10]. Zhang et al [6] prepared nc-TiN/a-SiN ${ }_{\mathrm{x}}$ nanocomposite films with hardness about $40 \mathrm{GPa}$ through reactive magnetron sputtering. Zhou et al [7] reported Ti-Si-N nanocomposite film had a maximum hardness of $47 \mathrm{GPa}$. In reactive sputtering processes, the microstructure and properties of the Ti-Si-N nanocomposite films strongly depend on the processing parameters such as bias voltage, nitrogen partial pressure, substrate temperature and the content of silicon [7-10]. Because

*Corresponding author: ccllhhe@126.com 
relative less information about effect of $\mathrm{N}_{2}$ flow rate on adhesion strength and friction coefficient of Ti-Si-N nanocomposite films, in this paper Ti-Si-N nanocomposite films were prepared by co-sputtering Ti and Si targets in $\mathrm{Ar} / \mathrm{N}_{2}$ gas atmosphere, and the effect of $\mathrm{N}_{2}$ flow rate on the microstructure, adhesion strength and friction coefficient of the deposited films was investigated in details.

\section{Materials and methods}

The Ti-Si-N nanocomposite films were deposited on polished AISI 304 stainless steel substrate with dimensions of $25 \mathrm{~mm} \times 25 \mathrm{~mm} \times 2 \mathrm{~mm}$ by co-sputtering Ti and Si targets in $\mathrm{Ar} / \mathrm{N}_{2}$ gas atmosphere using reactive magnetron sputtering. Pure Ti (99.99\%) and $\mathrm{Si}$ $(99.999 \%)$ targets of diameter $60 \mathrm{~mm}$ and thickness $4 \mathrm{~mm}$ were mounted about $80 \mathrm{~mm}$ below the substrate. The base pressure of the deposition chamber was pumped to $6.0 \times 10^{-4} \mathrm{~Pa}$ and the process pressure was fixed at $1.9 \mathrm{~Pa}$. High purity $\operatorname{Ar}(99.999 \%)$ and $\mathrm{N}_{2}(99.999 \%)$ gases were used. Ar gas flow rate was fixed at $10 \mathrm{sccm}$ while $\mathrm{N}_{2}$ gas flow rate was changed during deposition. The substrates were cleaned and in-situ sputter etched for $15 \mathrm{~min}$ in a pure Ar atmosphere before deposition. The current applied on Ti target was $0.2 \mathrm{~A}$ (DC), and the $\mathrm{RF}$ voltage on Si target was $100 \mathrm{~V}$. The bias voltage applied was $-120 \mathrm{~V}$, the depositing temperature and time was $300^{\circ} \mathrm{C}$ and $30 \mathrm{~min}$, respectively.

The crystal structure was analyzed by X-ray diffraction (XRD, PANalytical B.V. X Pert Pro MPD) with a Cu-K $\mathrm{K}_{\alpha} 40 \mathrm{kV} / 40 \mathrm{~mA}$ X-ray source (wavelength $\lambda=0.154056 \mathrm{~nm}$ ) at a low incident angle of $2^{\circ}$ and in the scanning angular $(2 \theta)$ range from $20^{\circ}$ to $90^{\circ}$ at $2 \% \mathrm{~min}$. The surface morphology and roughness of the deposited films were measured by atomic force microscopy (AFM,Agilent 5500) in tapping mode, and the surface and cross sectional morphology was observed using field emission scanning electron microscopy (FESEM, $\mathrm{S} 4800$, Hitachi) operated at $3-5 \mathrm{kV}$ voltage. The film/substrate adhesion strength was measured by scratch test, and the friction coefficient was evaluated by reciprocating friction method with MFT-4000 multi-functional tester for material surface properties (Lanzhou Institute of Chemical Physics Chinese Academy of Sciences).

\section{Results and discussion}

The XRD patterns of the Ti-Si-N thin films deposited at different $\mathrm{N}_{2}$ flow rate are shown in Fig.1. The diffraction peaks of TiN (B1 $\mathrm{NaCl}$-typed structure) and stainless steel occur in the XRD patterns, and no crystalline TiSi and $\mathrm{Si}_{3} \mathrm{~N}_{4}$ are found. The diffraction peaks of TiN phase are contributed to (200), (111), (220) and (222) crystallographic planes, and a dominant orientation of the (200) plane is exhibited. For TiN the surface energy for the (111), (200) and (220) planes are 400, 230 and $260 \mathrm{~J} . \mathrm{m}^{-2}$, respectively [11]. The (200) plane is the plane of the lowest surface energy in the TiN crystal. Therefore, when the surface energy is the main drive force the TiN crystallites orient on (200) plane. Because the Ti-Si-N films are very thin, the substrate

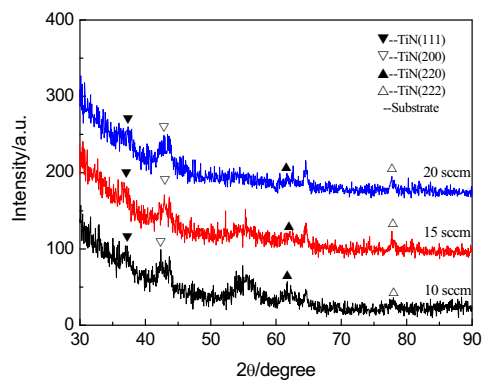

Fig.1 XRD patterns of the Ti-Si-N nanocomposite underneath the films could be detected. Because $\mathrm{Si}_{3} \mathrm{~N}_{4}$ phase could be formed under the present preparation conditions, no XRD signals corresponding to crystalline $\mathrm{Si}_{3} \mathrm{~N}_{4}$ phase mean that $\mathrm{Si}_{3} \mathrm{~N}_{4}$ is amorphous. The amorphous $\mathrm{Si}_{3} \mathrm{~N}_{4}$ encapsulates the growing TiN crystallites, preventing their growth [5]. 
Fig.1 also reveals that the intensities of (111) and (220) diffraction peaks of TiN crystallites gradually decrease when the $\mathrm{N}_{2}$ flow rate increases. Meanwhile, the (200) diffraction peak of TiN broadens with increasing $\mathrm{N}_{2}$ flow rate. These results above show that the increase in $\mathrm{N}_{2}$ flow rate is beneficial for the grain refinement of TiN in the nanocomposite film. This may be because increasing $\mathrm{N}_{2}$ flow rate can result in more a- $\mathrm{Si}_{3} \mathrm{~N}_{4}$ formed [9], inhibiting the growth of TiN grains [5].

The average grain size can be estimated by the Debye-Scherrer formula:

$$
\mathrm{D}=\mathrm{K} \lambda /(\beta \cos \theta)
$$

Where $\mathrm{K}$ is a constant $(\mathrm{K}=0.91), \mathrm{D}$ is the mean crystalline dimension normal to diffracting planes, $\lambda$ is the $\mathrm{X}$-ray wavelength, $\beta$ in radian is the peak width at half-maximum height and $\theta$ is the Bragg's angle. The calculated grain sizes of the TiN crystallites based on the (200) plane diffraction peak according to formula (1) are $6.4 \mathrm{~nm}, 4.5 \mathrm{~nm}$ and $4.6 \mathrm{~nm}$ for the $\mathrm{N}_{2}$ flow rates of 10,15 and $20 \mathrm{sccm}$, respectively. All the average grain sizes are fairly small and the film deposited at higher $\mathrm{N}_{2}$ flow rate has the finest structure. Zhang [12] reported the average grain size of sputtered TiN film produced under a similar condition was $10.4 \mathrm{~nm}$, larger than that of the TiN in the Ti-Si-N nanocomposite films in the present study, showing the preventing grain growth from the amorphous $\mathrm{Si}_{3} \mathrm{~N}_{4}$ is obvious.

AFM surface morphologies of the Ti-Si-N nanocomposite films deposited at different $\mathrm{N}_{2}$ flow rate are shown in Fig.2. When the $\mathrm{N}_{2}$ flow rate is lower (at $10 \mathrm{sccm}$ ), a small quantity of amorphous $\mathrm{Si}_{3} \mathrm{~N}_{4}$ phase is formed due to less $\mathrm{N}$ particles in ionization gas, and they may not effectively encapsulate TiN grains, weakening the refining effect to some extent. As a result, the structure is a little larger. The root mean square roughness (RMS) is $2.21 \mathrm{~nm}$. When the $\mathrm{N}_{2}$ flow rate increases to $15 \mathrm{sccm}$, more amorphous $\mathrm{Si}_{3} \mathrm{~N}_{4}$ can be formed, resulting in enhancing grain refinement effect. The RMS is $2.53 \mathrm{~nm}$. However, when the $\mathrm{N}_{2}$ flow rate reaches to $20 \mathrm{sccm}$, the film surface is fine, but its RMS reaches to $3.47 \mathrm{~nm}$. Although the RMS gradually increases with increasing $\mathrm{N}_{2}$ flow rate as shown in Fig.2d, it is still very small, showing the film has a smooth surface.

Fig.3 presents the FESEM surface and cross sectional morphologies of the deposited film produced at $\mathrm{N}_{2}$ flow rate of $15 \mathrm{sccm}$, showing that the film is fine, smooth, dense and compact with a columnar structure. Our experimental results show that the thickness for the nanocomposite films deposited at different $\mathrm{N}_{2}$ flow rate is approximately $167-175 \mathrm{~nm}$, almost independent of the $\mathrm{N}_{2}$ flow rate [13].
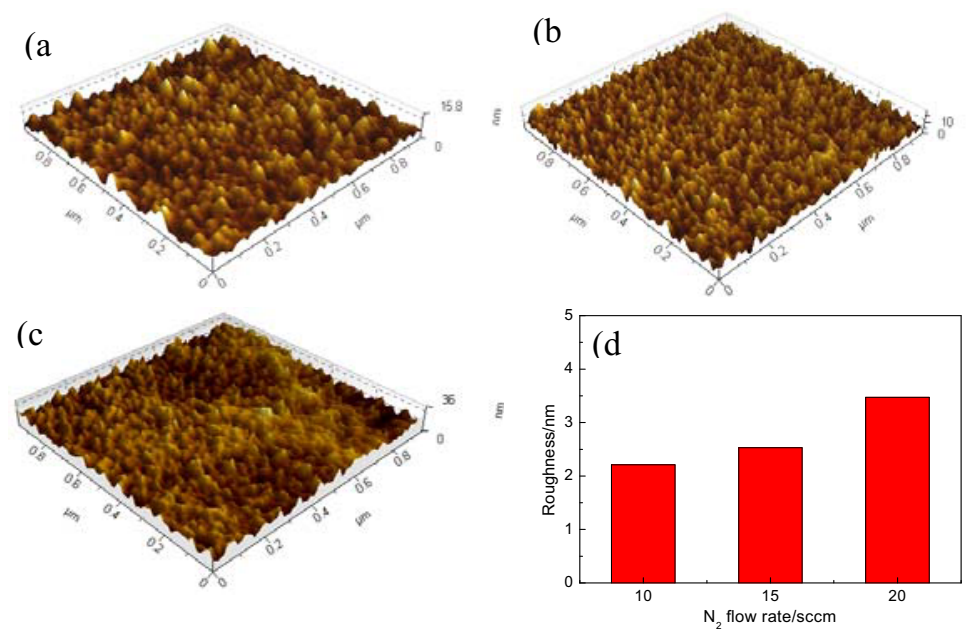

Fig.2 AFM 3D-morphologies roughness of Ti-Si-N nanocomposite films deposited at different $\mathrm{N} 2$ flow rate. (a) $10 \mathrm{sccm}$, (b) $15 \mathrm{sccm}$, (c) $20 \mathrm{sccm}$, (d) roughness 

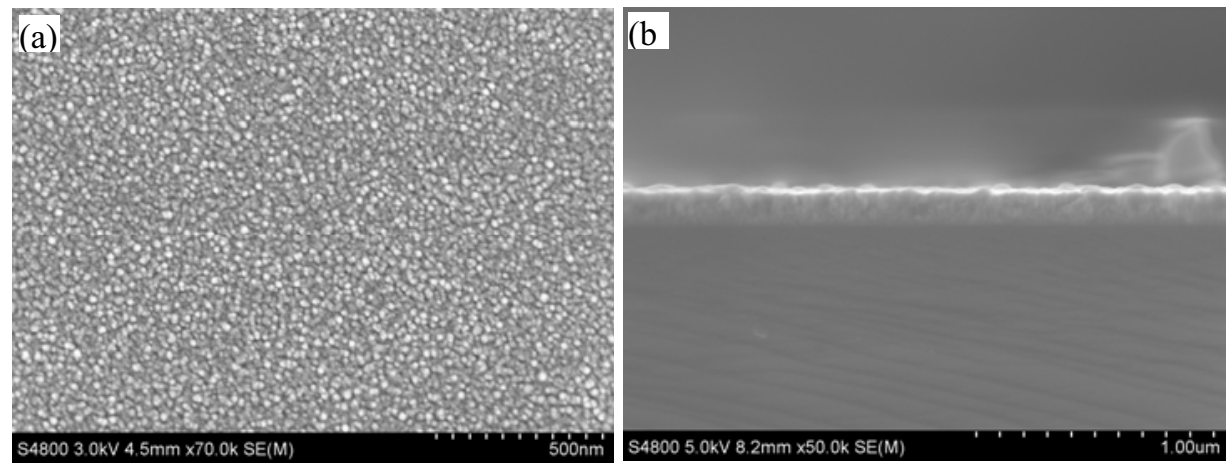

Fig.3 The FESEM surface (a) and cross sectional (b) morphologies of the nanocomposite film produced at $\mathrm{N} 2$ flow rate of $15 \mathrm{sccm}$

The film/substrate adhesion strength is usually measured through scratch test, it is expressed by the critical load i.e. the lowest pressure force inducing the adhesive failure. Variations of acoustic emission signal intensity with load force applied on the Ti-Si-N film/AISI 304 system during scratching are shown in Fig.4. When the $\mathrm{N}_{2}$ flow rate is 10,15 and $20 \mathrm{sccm}$, the film/substrate adhesion strength is 52,56 and $37 \mathrm{~N}$, respectively. The adhesion strength first increases and then decreases as the $\mathrm{N}_{2}$ flow rate increases, and it reaches a maximum value at $\mathrm{N}_{2}$ flow rate of $15 \mathrm{sccm}$. This is associated with the finer and smoother structure of the nanocomposite film produced at $15 \mathrm{sccm}$ as shown in Fig.2b and Fig.3a. The excellent adhesion strength of such film may play a positive role in the cutting performance [9]. The film produced at $\mathrm{N}_{2}$ flow rate of $20 \mathrm{sccm}$ has the lowest adhesion strength, perhaps resulting from its most amorphous $\mathrm{Si}_{3} \mathrm{~N}_{4}$ and highest brittleness [7,9].

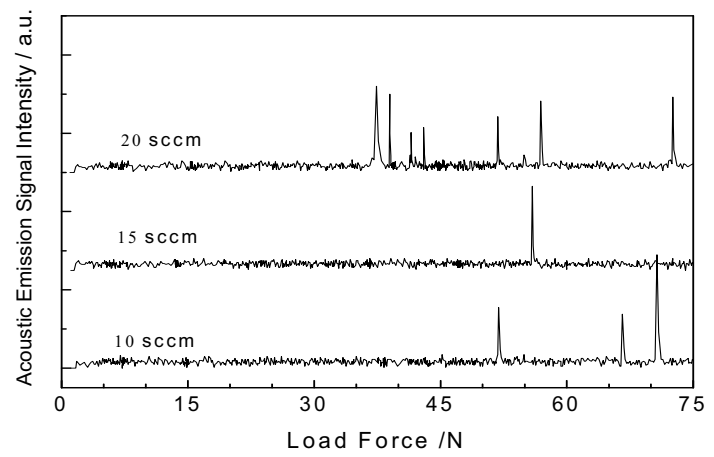

Fig.4 Variation of acoustic emission signal with N2 flow rate during scratching. 

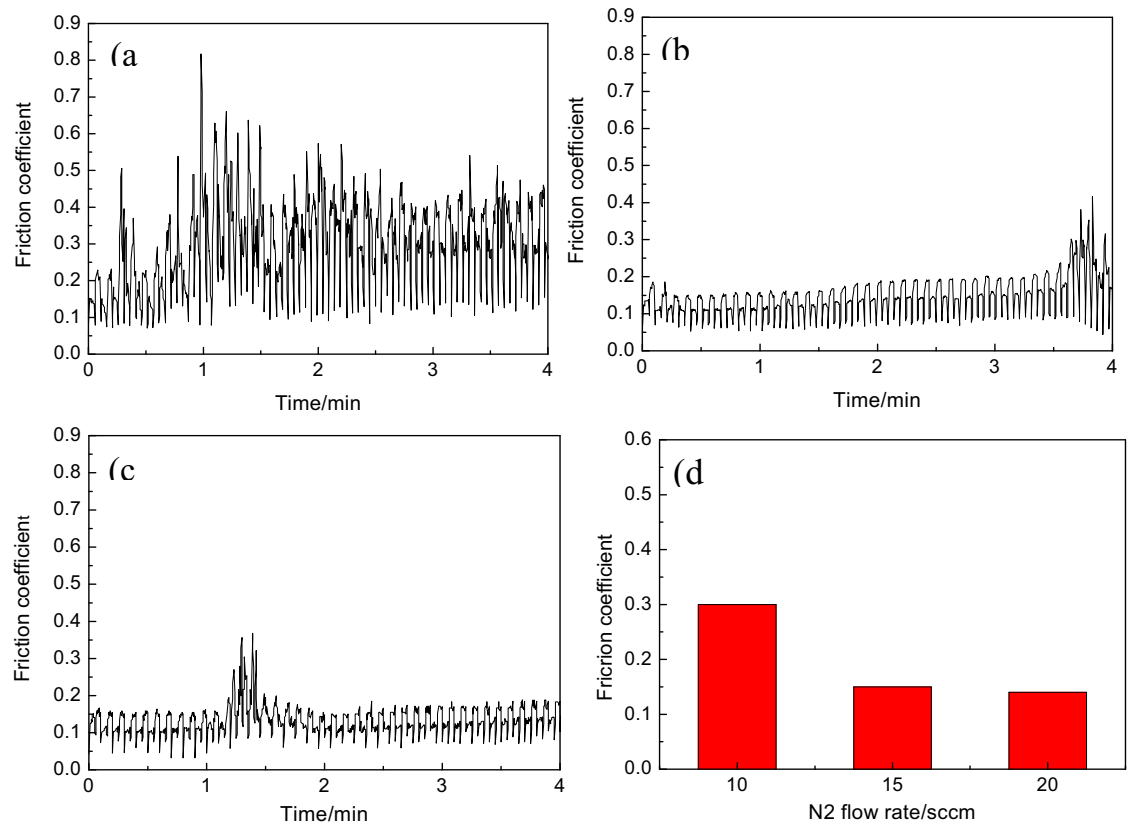

Fig.5 Variations of friction coefficient of the Ti-Si-N films fabricated at different $\mathrm{N}_{2}$ flow rate.

(a) $10 \mathrm{sccm}$, (b) $15 \mathrm{sccm}$, (c) $20 \mathrm{sccm}$, (d) comparison of friction coefficient.

Variations of friction coefficient of the Ti-Si-N nanocomposite films with friction time measured by reciprocating friction method using $\mathrm{Si}_{3} \mathrm{~N}_{4}$ ball as a counterpart material are shown in Fig.5. When the $\mathrm{N}_{2}$ flow rate is 10,15 and $20 \mathrm{sccm}$, the average friction coefficient of the Ti-Si-N nanocomposite films is $0.30,0.15$ and 0.14 , respectively. The friction coefficient is very small and decreases as the $\mathrm{N}_{2}$ flow rate increases. In fact, it almost does not change when the $\mathrm{N}_{2}$ flow rate exceeds $15 \mathrm{sccm}$ (Fig. $5 \mathrm{~d}$ ). This is associated with the finer structure of the nanocomposite film produced at higher $\mathrm{N}_{2}$ flow rate.

\section{Summary}

Ti-Si-N nanocomposite films were deposited at different $\mathrm{N}_{2}$ flow rate by co-sputtering $\mathrm{Ti}$ and $\mathrm{Si}$ targets in $\mathrm{Ar} / \mathrm{N}_{2}$ gas atmosphere. The deposited films possess nc-TiN/a-Si $\mathrm{N}_{4}$ nanocomposite structure, and exhibit (200), (111), (220) and (222) reflections with a dominant orientation of the (200) plane. The Ti-Si-N nanocomposite films are fine and smooth with a columnar structure. When $\mathrm{N}_{2}$ flow rate increases, the grain size of the deposited films gradually decreases whereas the RMS slightly increases. However, the film thickness is almost independent of the $\mathrm{N}_{2}$ flow rate. The scratch tests show that the adhesion strength first increases and then decreases as the $\mathrm{N}_{2}$ flow rate increases, and its maximum value is $56 \mathrm{~N}$ for the film produced at $15 \mathrm{sccm}$, contributed to its finer and smoother structure. The friction coefficient of the deposited films is very small and decreases as the $\mathrm{N}_{2}$ flow rate increases. 


\section{Acknowledgements}

This work was supported by Program for Liaoning Excellent Talents in University (LR2013054), the Project-sponsored by SRF for ROCS, SEM and the National Natural Science Foundation (51171118) of China.

\section{References}

1. J. Musil, J. Vlcek, A perspective of magnetron sputtering in surface engineering, Surf. Coat. Technol. 112 (1999) 162-169.

2. G.H. Song, H. Du, C.L. He: Hard and Superhard Coatings, Beijing, Chemical Industry Press, 2007.

3. S. Veprek, S. Reiprich, L. Shizhi, Superhard nanocrystalline composite materials: The TiN/Si3N4 system, Appl. Phys. Lett. 66 (1995) 2640-2642.

4. S. Veprek, P. Nesladek, A. Niederhofer, F. Glatz, M. Jilek, M. Sima, Recent progress in the superhard nanocrystalline composites: towards their industrialization and understanding of the origin of the superhardness, Surf. Coat. Technol. 108-109 (1998) 138-147.

5. S. Veprek, A. Niederhofer, K. Moto, T. Bolom, H.D. Männling, P. Nesladek, G. Dollinger, A. Bergmaier, Composition, nanostructure and origin of the ultrahardness in nc-TiN/a-Si3N4/a- and nc-TiSi2 nanocomposites with HV=80 to $\geq 105 \mathrm{GPa}$, Surf. Coat. Technol. 133-134 (2000) 152-159.

6. S. Zhang, D. Sun, Y. Fu, H. Du, Effect of sputtering target power on microstructure and mechanical properties of nanocomposite nc-TiN/a-SiNx thin films, Thin Solid Films 447-448 (2004) 462-467.

7. Z.F. Zhou, B. Zhao, P.W. Shum, K.Y. Li, Mechanical behaviors of Ti-Si-N coatings deposited by bias sputtering, Rare Metal Mater. Eng. 41(S1) (2012)18-23.

8. X. Hu, G. Li, J. Dai, Z. Ding, M. Gu, Influences of Si content and substrate temperature on Ti-Si-N nanocomposite films, Journal of Shanghai Jiaotong University 37 (2003) 252-256.

9. L. Pan, Y. Bai, D. Zhang, J. Wang, Ti-Si-N films prepared by magnetron sputtering, Rare Metals 31 (2012) 183-188.

10. M. Diserens, J. Patscheider, F. Levy, Improving the properties of titanium nitride by incorporation of silicon, Surf. Coat. Technol. 108-109 (1998) 241-246.

11. S. Zhang, D. Sun, Y. Fu, H. Du, Q. Zhang, Effect of sputtering target power on preferred orientation in nc-TiN/a-SiNx nanocomposite thin films, Journal of Metastable and Nanocrystalline Materials 23 (2005) 175-178.

12. J. L. Zhang, Preparation and properties of metal toughened TiN/AlN nano multilayered films deposited by magnetron sputtering, M. S. thesis, Shenyang University, Shenyang, China, 2012.

13. L. Pan, Research on nanocomposite Ti-Si-N films prepared by magnetron sputtering, M.S. thesis, Dalian University of Technology, Dalian, China, 2011. 